\title{
Use of Boey's score in peptic perforation disease in the Nepalese population: a prospective observational study
}

\author{
Rabin Koirala ${ }^{1}$, Paras Pant ${ }^{1}$, Nikhil Acharya ${ }^{2}$, Asish Rajbhandary ${ }^{1}$ \\ ${ }^{1}$ Department of Surgery, Nepal Medical College and Teaching Hospital, Attarkhel, Jorpati, Kathmandu, Nepal \\ ${ }^{2}$ Helping Hands Community Hospital, Kathmandu, Nepal \\ Correspondence: Dr. Rabin Koirala, Department of Surgery, Nepal Medical College and Teaching Hospital, Attarkhel, \\ Jorpati, Kathmandu, Nepal \\ Email: rabinkoirala@hotmail.com
}

\section{Abstract}

Introduction: Peptic ulcer perforation carries high mortality and morbidity. Boey's score is shown to be a simple scoring system to help predict morbidity and mortality. This is a prospective observational study to evaluate the applicability of Boey's score in predicting mortality and morbidity in Nepalese patients.

Methods: This study was conducted in the Dept. of Surgery, Nepal Medical College and Teaching Hospital (NMCTH), Attarkhel, Jorpati between $1^{\text {st }}$ of July 2012 to $30^{\text {th }}$ June 2019 over a period of 7 years. This was a prospective observational study. All patients who underwent laparotomy for suspected peptic ulcer perforation peritonitis were included in the study.

Results: Fourty-seven patients were included in the study. Male patients outnumbered females by a ratio of almost 4:1. Eighteen (38\%) patients had Boey's score of 1, and 7 (15\%) patients had a Boey's score of 3. Overall postoperative mortality was $7(15 \%)$. Boey's score predicted morbidity and mortality with a p-value of $<0.01$. The length of hospital stay was also more in patients with a higher score and it was statistically significant.

Conclusions: Boey's score is both easy and effective in predicting postoperative morbidity, mortality and length of hospital stay.

Keywords: Boey’s Score; Peptic Ulcer Perforation; Peritonitis.

\section{Introduction}

Peptic ulcer affects more than 4 million people annually. ${ }^{1}$ Western studies put the prevalence at between 5 to $15 \% .^{2,3}$ Perforation occurs in $2-14 \%$ of patients with duodenal ulcers and carries high mortality of up to $25 \%-30 \% .^{2,3}$ During the last three decades there has been a significant drop in elective surgery for the peptic ulcer but surgery for complications of peptic ulcer has not declined significantly. In fact, the incidence of peptic ulcer perforation and bleeding rates has increased according to some studies and they attribute this to an aging population and increased NSAID use. ${ }^{4-6}$ Increasing age, associated comorbid conditions, presence of shock in the perioperative period and delayed presentation or management are associated with poor outcomes. ${ }^{6}$ A simple effective predictive model can be a very useful tool in prognosticating and identifying patients at risk of increased morbidity and mortality. In 1987, Boey and colleagues introduced a simple preoperative risk stratification score. They include the presence of major medical illness, preoperative shock, and perforation presenting after 24 hours or more. ${ }^{7}$ In our study, we use Boey's score to see if it is applicable in our population.

\section{Methods}

This study was conducted in the Department of Surgery, Nepal Medical College and Teaching Hospital between $1^{\text {st }}$ of July 2012 and $30^{\text {th }}$ June 2019 for a period of 7 years. This was a prospective observational study. All patients who underwent laparotomy for suspected peptic ulcer 
perforation peritonitis were included in the study. If patients were found to have other sites of perforation they were excluded from the study. Patients with other cause of peptic ulcer perforations, like iatrogenic, traumatic or associated malignancy were also excluded from the study. All the patients underwent upper midline laparotomy and modified Graham's patch repair after refreshing the margins. Lavage with warm saline and drain in Morrison's pouch was kept in all the cases. Patients were discharged once the patients were taking an adequate oral diet and stable. All patients were given anti Helicobacter pylori treatment empirically. None of the cases were done laparoscopically. The data was entered in SPSS software version 16 and statistical analysis was done using the chi-square test and a p-value of less than 0.05 was considered significant. Approval was taken from the institutional review board for the study.

\section{Results}

During the study period of 7 years, a total of 49 cases underwent surgery for Peptic ulcer perforation at our institute. Two patients were excluded from the study. One was an iatrogenic duodenal perforation after laparoscopic cholecystectomy and the other had a concurrent obstructed inguinal hernia. The remaining 47 were included in the study. Male patients outnumbered females by a ratio of almost $4: 1$; out of 47 patients 37 (79\%) were male and $10(21 \%)$ were female. In our study, the maximum number of patients belonged to the age group of $30-40$ years $(23 \%)$. Table 1 . Only 6 or $(13 \%)$ of the patients were above 60 years old. Figure 1.

\section{Table 1: General patient characteristics}

\begin{tabular}{ll}
\hline Patient characteristics & Mean_SD \\
\hline Age & $39.48 \pm 16.44$ \\
Sex & $\mathrm{M}: \mathrm{F}=3.7: 1$ \\
Total Count & $11640.57 \pm 3381.8$ \\
Neutrophil & $85.14 \pm 9.53$ \\
Serum albumin & $3.1 \pm 0.75$ \\
Creatinine & $0.77 \pm 0.25$ \\
Amylase & $125.38 \pm 98.78$ \\
Lipase & $121.34 \pm 128.38$ \\
Hb & $12.42+2.11$ \\
Pulse & $103 \pm 13.33$ \\
SBP & $101.61 \pm 16.98$ \\
DBP & $66.85 \pm 10.79$ \\
MAP & $78.43 \pm 12.12$ \\
\hline
\end{tabular}

Figure 1: Age distribution of the patients

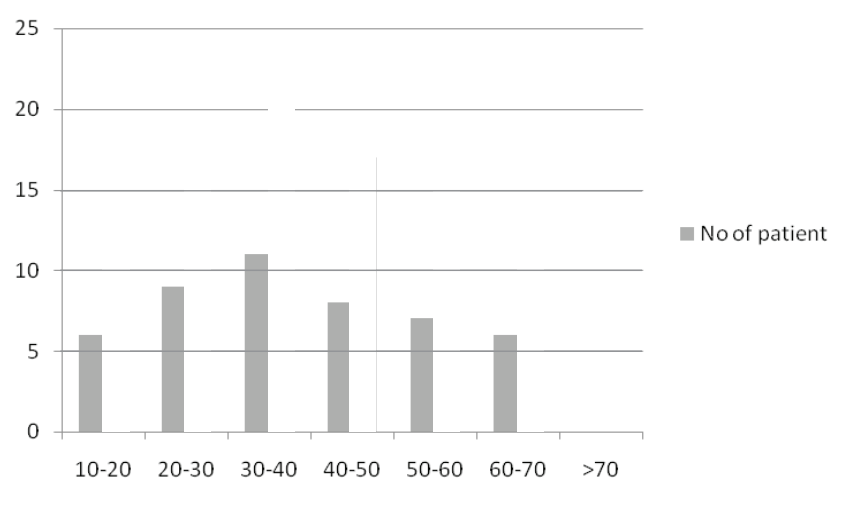

Among the important risk factors, 10 (21\%) patients consumed alcohol regularly (minimum 3 times a week) but a further $29(62 \%)$ consumed alcohol occasionally. There were $14(30 \%)$ smokers in this group of patients and 5 (11 $\%$ ) patients were taking NSAIDs at the time of perforation.

Pneumoperitoneum was seen in up to $40(85 \%)$ patients on plain $\mathrm{x}$-ray of chest/abdomen, and in the remaining 7 (14\%) cases CT scan showed pneumoperitoneum. Table 2. Preoperative shock was seen in $9(19 \%)$ patients and 18 (38 $\%$ ) patients presented to the hospital after 24 hours of the onset of acute abdominal pain. Seven (15\%) patients had a concomitant medical illness and were under medication.

Table 2: Imaging modality detecting pneumoperitoneum

\begin{tabular}{lll}
\hline Pneumoperitoneum & No. of patient & Percentage \\
\hline $\begin{array}{l}\text { Pneumoperitoneum } \\
\text { on X-ray }\end{array}$ & 40 & $85 \%$ \\
$\begin{array}{l}\text { Pneumoperitoneum } \\
\text { on CT }\end{array}$ & 7 & $15 \%$ \\
\hline
\end{tabular}

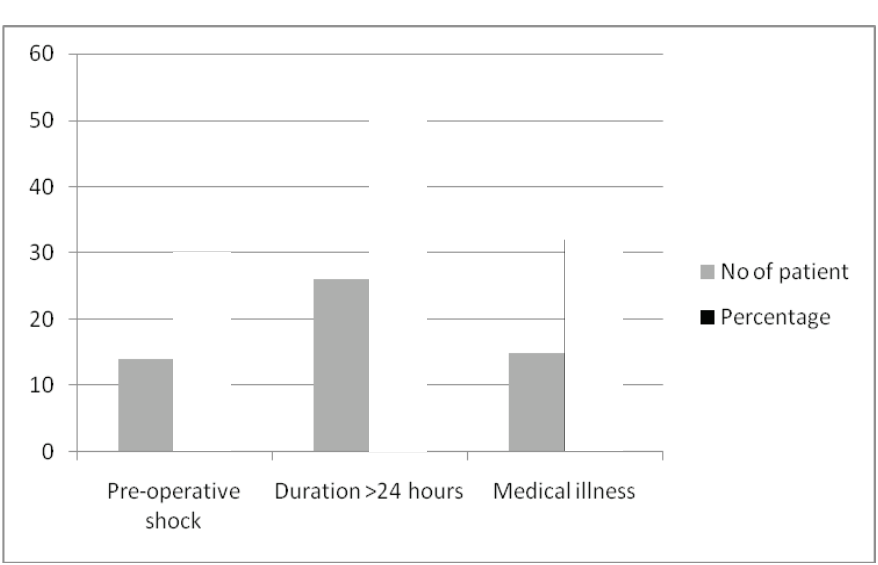

Figure 2: Number of patients positive for different Boey's Parameters 
In our study maximum number of patients had Boey's score of 1 . Table 3 shows the number of patients in each Boey's score category. Eighteen (38\%) patients had Boey's score of 1 , and 7 (15\%) patients had a Boey's score of 3 . The most common site of perforation was D1 (first part of duodenum) seen in 35 patients (74\%). This was followed by pre-pyloric ulcers in 10\% (21\%) and lesser curvature in $2(5 \%)$ of the patients.

Most patients had a perforation of size between $0.5-1 \mathrm{~cm}$ (64\%). Table 4.

Table 3: Boey's Score

\begin{tabular}{ll}
\hline Boey's score & N (\%) \\
\hline 0 & $14(30 \%)$ \\
1 & $18(38 \%)$ \\
2 & $8(17 \%)$ \\
3 & $7(15 \%)$ \\
TOTAL & $47(100 \%)$ \\
\hline
\end{tabular}

Table 4: Size of perforation

\begin{tabular}{lll}
\hline Size in cm & Number & Percentage \\
\hline$<0.5$ & 0 & 0 \\
$0.5-1.0$ & 30 & 64 \\
$1.0-1.5$ & 14 & 30 \\
$>1.5$ & 3 & 6 \\
\hline
\end{tabular}

Overall postoperative mortality was 7 (15\%). Most of the patients died due to postoperative complications with the most common being chest infection leading to septicemia and multi-organ failure. Postoperative mortality was directly associated with the delayed presentation in hospital and preoperative shock and concomitant medical illness. Mortality was higher in the age group of more than 60 . Mortality and morbidity were higher in males but this was not statistically significant. Mortality was not associated with the size of perforation (P-value $=0.59$ ).

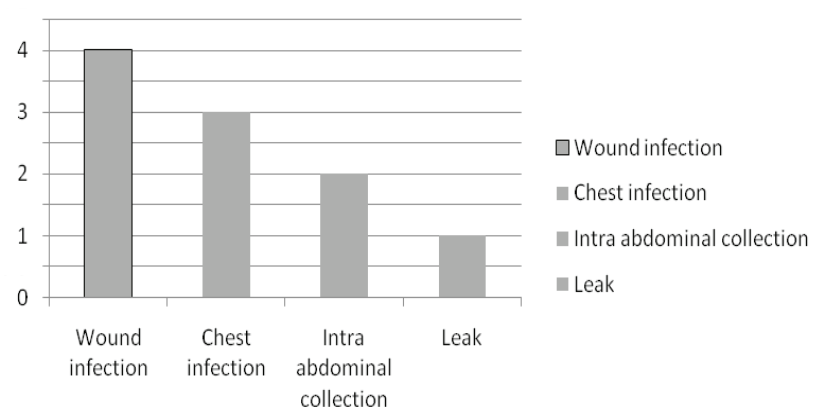

Figure 3: Complications

Table 5: Boey's score and Morbidity

\begin{tabular}{lllll}
\hline $\begin{array}{l}\text { Boey's } \\
\text { score }\end{array}$ & Total & $\begin{array}{l}\text { Morbidity } \\
\text { Frequency }\end{array}$ & $\begin{array}{l}\text { Morbidity } \\
\text { Percentage }\end{array}$ & P-value* \\
\hline 0 & 14 & 0 & $0 \%$ & $<\mathbf{0 . 0 1}$ \\
1 & 18 & 1 & $6 \%$ & \\
2 & 8 & 2 & $25 \%$ & \\
3 & 7 & 7 & $100 \%$ & \\
\hline
\end{tabular}

*Chi-square test

Table 6: Boey's score and mortality

\begin{tabular}{lllll}
\hline $\begin{array}{l}\text { Boey's } \\
\text { score }\end{array}$ & Total & $\begin{array}{l}\text { Morbidity } \\
\text { Frequency }\end{array}$ & $\begin{array}{l}\text { Morbidity } \\
\text { Percentage }\end{array}$ & P value* \\
\hline 0 & 14 & 0 & $0 \%$ & $<\mathbf{0 . 0 1}$ \\
1 & 18 & 1 & $6 \%$ & \\
2 & 8 & 2 & $25 \%$ & \\
3 & 7 & 5 & $71 \%$ & \\
\hline
\end{tabular}

*Chi-square test

\section{Table 7: Boey's score and length of hospital stay}

\begin{tabular}{lllllllll}
\hline $\begin{array}{l}\text { Boey's } \\
\text { score }\end{array}$ & $\begin{array}{l}\text { Length of hospital stay } \\
<4 \text { days } \\
\text { frequency }\end{array}$ & percentage & $\begin{array}{l}\mathbf{5 - 8} \text { days } \\
\text { frequency }\end{array}$ & percentage & $\begin{array}{l}>\text { 9 days } \\
\text { frequency }\end{array}$ & percentage & Total & P Value * \\
\hline 0 & 8 & $57.1 \%$ & 6 & $42.9 \%$ & 0 & $0.0 \%$ & 14 & \\
1 & 0 & $0.0 \%$ & 18 & $100 \%$ & 0 & $0.0 \%$ & 18 & \\
2 & 0 & $0.0 \%$ & 8 & $100 \%$ & 0 & $0.0 \%$ & 8 & $<0.001$ \\
3 & 0 & $0.0 \%$ & 0 & $0.0 \%$ & 7 & $100 \%$ & 7 & \\
Total & 8 & $17 \%$ & 32 & $68.1 \%$ & 7 & $14.9 \%$ & 47 & \\
\hline
\end{tabular}

*Chi-square test 
The mortality increased progressively with increasing numbers in Boey's score; $0 \%, 6 \%, 25 \%$ and $71 \%$ for $0,1,2,3$ respectively and this relation was statistically significant with a $\mathrm{p}$-value of $<0.01$. The morbidity increases progressively with an increase in Boey's score; $0 \%, 6 \%$, $25 \%$, and $100 \%$ respectively for Boey's score of $0,1,2$ and 3 respectively. This was statistically significant with a p-value of $<0.01$. The association between Boey's score and length of hospital stay was also very significant. Table 7. All patients with Boey's score of 2 or more had a hospital stay of more than 9 days while none in Boey's score of 0 and 1 stayed for more than 8 days.

Thirty-seven of the 47 patients had albumin levels below $3.5 \mathrm{gm} / \mathrm{dl}$. Though decreased albumin was associated with increased mortality; it was not statistically significant $(\mathrm{P}=0.14)$.

In $12(26 \%)$ patient serum amylase was more than 180 IU/L or more than thrice the institutional normal limit but serum lipase was raised (>160 IU/L) in only $2(4.25 \%)$ cases in our study. This had no bearing on morbidity and mortality.

\section{Discussion}

Perforation occurs in $2-10 \%$ of patients with peptic ulcer disease and accounts for $70 \%$ of the mortality. ${ }^{9}$ The mortality in our study was $15 \%$ which was comparable to between $14-27 \%$ reported in other studies and $18 \%$ quoted in a Nepalese study. ${ }^{9-12}$ The morbidity in our study was $21 \%$ which compares favorably with most reported literature. The literature reports rates of between $14-61 \%{ }^{10-15}$

Our patients presented at a younger age compared to patients from other western studies. ${ }^{10,11,13}$ The proportionately larger number of smokers and drinkers and relatively low incidence of NSAID use may be explained by younger male patients in our study. Other studies also show lower NSAID use in the young. ${ }^{18-20}$ As in other studies, our study also shows pulmonary and wound-related complications to be the major source of morbidity. ${ }^{9,10,12,13-15}$ The commonest site of perforation in peptic ulcers in our study was the 1st part of the duodenum. This has been reported by most other studies. ${ }^{12,14,16-18}$ The above finding suggests we have a different patient profile of peptic ulcer perforation compared to the west.

Mortality correlates with Boey's score. Mortality in our study was $0 \%, 6 \%, 25 \%$ and $71 \%$ for Boey's score of $0,1,2,3$ respectively and this relation was statistically significant with a p-value of $<0.01$. This compares with other studies. Sah DN and colleagues ${ }^{12}$ report mortality of $5.3 \%, 6.7 \%, 36.4 \%$ and $60 \%$ with Boey's score of patients 0, 1, 2 and 3 and a study by Agrawal A et al ${ }^{14}$ report mortality rates of $1.9 \%, 7.1 \%, 31.7 \%$, and $40 \%$ for $0,1,2$, and 3 scores, respectively.

Morbidity also correlates with Boey's score with morbidity rates of $0 \%, 6 \%, 25 \%$ and $100 \%$ for scores of $0,1,2$ and 3 respectively, $\mathrm{P}$ value $<0.01$.

The length of hospital stay with the higher score was longer in our study and was significant $p<0.001$. This has been corroborated by other studies. Menekse E et $\mathrm{al}^{21}$ found the mean length of hospital stay was 7.9 \pm 9.0 days (ranged 1-115). Another study conducted by Gulzar JS et $\mathrm{al}^{22}$ compared the length of hospital stay with different Boey's score groups and concluded length of hospital stay increases with an increase in Boey's score with $p$ value $<0.01$.

Other Scoring systems have been used and have been found to be useful in predicting mortality and morbidity in patients with perforated peptic ulcers.

Møller MH, et $\mathrm{al}^{11}$ developed the Peptic Ulcer Perforation (PULP) score based on age, presence of comorbid diseases, presence of shock at admission, steroid use, serum creatinine, the time duration between onset of symptoms to admission and ASA scores. While it is a good predictor of morbidity and mortality it is significantly more complex than Boey's score.

ASA scores have been evaluated and associated with mortality and morbidity in patients with peptic ulcer perforation but they were relatively small studies. ${ }^{10,23}$ The Mannheim Peritonitis Index (MPI) uses a score of between 0 to 47 multivariable system with eight adverse factors which comprise both preoperative and perioperative conditions. While studies have shown they are effective means of predicting mortality and morbidity, they are much more complex. ${ }^{24-26}$

\section{Conclusion}

Boey's score is both easy and effective in predicting postoperative morbidity, mortality, and length of hospital stay.

\section{References}

1. Bertleff MJ, Lange JF. Perforated peptic ulcer disease: a review of history and treatment. Dig Surg. 2010 Aug;27(3):161-9.

2. Aro P, Storskrubb T, Ronkainen J, Bolling-Sternevald E, Engstrand L, Vieth $M$ et al. Peptic ulcer disease in a general adult population. The Kalixanda study: a random population-based study. Am J Epidemiol. 2006 Jun 1;163(11):1025-34

JSSN 2019; 22 (1) 
3. Behrman SW. Management of complicated peptic ulcer disease. Arch Surg. 2005 Feb;140(2):201-8.

4. Moller $\mathrm{MH}$, Shah $\mathrm{K}$, Bendix J, Jensen $\mathrm{AG}$, Zimmermann-Nielsen E, Adamsen $\mathrm{S}$ et al. Risk factors in patients surgically treated for peptic ulcer perforation. Scand J Gastroenterol. 2009; 44(2):145152.

5. Sarosi Jr GA, Jaiswal KR, Nwariaku FE, Asolati M, Fleming JB, Anthony T. Surgical therapy of peptic ulcers in the 21st century: more common than you think. Am J Surg. 2005 Nov;190(5):775-9.

6. Lee CW, Sarosi Jr GA. Emergency ulcer surgery. Surg Clin North Am. 2011 Oct;91(5):1001-13.

7. Di Saverio S, Bassi M, Smerieri N, Masetti M, Ferrara F, Fabbri C. Diagnosis and treatment of perforated or bleeding peptic ulcers. World J Emerg Surg. 201; 9: 45.

8. Boey J, Choi SK, Poon A, Alagaratnam TT. Risk stratification in perforated duodenal ulcers- A prospective validation of predictive factors. Ann Surg. 1987 Jan; 205(1): 22-26.

9. Ramakrishnan K, Salinas RC. Peptic ulcer disease. Am Fam Physician. 2007 Oct 1;76(7):1005-12.

10. Makelä JT, Kiviniemi H, Ohtonen P, Laitinen SO. Factors that predict morbidity and mortality in patients with perforated peptic ulcers. Eur J Surg. 2002;168(89):446-51.

11. Møller MH, Engebjerg MC, Adamsen S, Bendix J, Thomsen RW. The Peptic Ulcer Perforation (PULP) score: a predictor of mortality following peptic ulcer perforation- a cohort study. Acta Anaesthesiol Scand. 2012; 56(5): 655-662.

12. Sah DN, Upadhyay PK. Scoring system in outcome prediction of postoperative mortality and morbidity in perforated peptic ulcer. Glob Surg. 2018; 4(3): 1-4.

13. Lunevicius R, Morkevicius M. Systematic review comparing laparoscopic and open repair for perforated peptic ulcer. Br J Surg. 2005 Oct;92(10):1195-207.

14. Agarwal A, Jain S, Meena LN, Jain SA, Agarwal L. Validation of Boey's score in predicting morbidity and mortality in peptic perforation peritonitis in Northwestern India. Trop Gastroenterol. 2015 OctDec;36(4):256-60.
15. So JBY, Yam A, Cheah WK, Kum CK, Goh PM. Risk factors related to operative mortality and morbidity in patients undergoing emergency gastrectomy. $\mathrm{Br} \mathrm{J}$ Surg. 2000 Dec;87(12):1702-7.

16. Lee F, Leung KL, Lai BS. Predicting mortality and morbidity of patients operated on for perforated peptic ulcer. Arch Surg. 2001 Jan;136(1):90-4.

17. Siu WT, Chau CH, Law BK, Tang CN, Ha PY, Li MK. Routine use of laparoscopic repair for perforated peptic ulcer. Br J Surg. 2004 Apr;91(4):481-4.

18. Barczynski M, Res F, Cichon S. Perioperative mortality for perforated duodenal and gastric ulcer-analysis of 226 patients. Prezeg Lek. 1999; 56(3): 192-7.

19. Janik J, Chwirot P. Perforated peptic ulcer-time trends and patterns over 20 years. 2000 Mar-Apr;6(2):369-72.

20. Lanas A, Serrano P, Bajador E, Esteva F, Benito R, Sáinz R., . Evidence of aspirin use in both upper and lower gastrointestinal perforation. Gastroenterology. 1997 Mar;112(3):683-9.

21. Menekse E, Kocer B, Topcu R, Olmez A, Tez M, Kayaalp C. A practical scoring system to predict mortality in patients with perforated peptic ulcer. World J Em Surg. 2015 Feb 21;10:7.

22. Gulzar JS, Paruthy SB, Arya SV. Improving outcome in perforated peptic ulcer emergency surgery by Boey scoring. Int Surg J. 2016 Nov;3(4):2120-8.

23. Lohsiriwat V, Prapasrivorakul S, Lohsiriwat D. Perforated peptic ulcer: clinical presentation, surgical outcomes, and the accuracy of the Boey scoring system in predicting postoperative morbidity and mortality. World J Surg. 2009 Jan;33(1):80-5.

24. Fitz-Henry J. The ASA classification and peri-operative risk. Ann R Coll Surg Engl. 2011 Apr;93(3):185-7.

25. Billing A, Fröhlich D, Schildberg FW. Prediction of outcome using the Mannheim peritonitis index in 2003 patients- Peritonitis Study Group. Br J Surg. 1994 Feb;81(2):209-13.

26. Linder MM, Wacha H, Feldmann U, Wesch G, Streifensand RA, Gundlach E. The Mannheim peritonitis index: An instrument for the intraoperative prognosis of peritonitis. Chirurg. 1987 Feb;58(2): 84-92. 